\title{
Fingerprint comparison evidence has been under sustained attack in the United States of America for the last number of years: Is the critique with regard to reliability sufficiently penetrating to warrant the exclusion of this valuable evidence?
}

\author{
WIUM DE VILLIERS ${ }^{1}$
}

\begin{abstract}
The decision in Daubert v Merrell Dow Pharmaceuticals 509 US 579 (1993) brought about renewed attention to and scrutiny of fingerprint comparison evidence in the United States of America. In terms of the decision, judges were to act as gatekeepers with respect to the admissibility of scientific expert evidence. The court also explicated a non-exhaustive list of factors to be utilised by judges when assessing the reliability of expert scientific evidence. This article describes these events and investigates the challenges with regard to reliability that were made to fingerprint comparison evidence in the American courts, as well as the position that was taken by the courts in the wake of these events. The article also discusses the fundamental test for the admission of expert evidence in jurisdictions with a strict system of evidence by using the USA and South Africa as examples, and considers whether the critique pointed out by the defendants in the cases are sufficiently penetrating to warrant the exclusion of fingerprint comparison evidence. In evaluating the critique, the article inter alia considers the practices and events with regard to fingerprint comparison in selected other jurisdictions, including that of prominent Commonwealth countries like England and Wales, Scotland and South Africa.
\end{abstract}

Keywords: fingerprints; fingerprint comparison evidence; ACE-V; individualization; expert evidence.

\section{A Introduction and background}

The 1993 decision of the United States Supreme Court in Daubert v Merrell Dow Pharmaceuticals ${ }^{2}$ brought about renewed attention to and scrutiny of fingerprint comparison evidence in the United States of America. Prior to Daubert expert evidence was allowed if it was generally accepted in the relevant scientific community. ${ }^{3}$ In Daubert the court held that the reliability of the scientific evidence in terms of Rule $702^{4}$ must be evaluated. The court held that judges were to act as the gatekeepers with respect to the admissibility of scientific evidence. $^{5}$

The court also articulated a non-exhaustive list of factors that a court should weigh when considering the admissibility of scientific expert evidence. The factors are 1) whether

\footnotetext{
${ }^{1}$ Bluris, LLB, LLD, Advocate of the High Court of South Africa, Associate Professor in the Department of Procedural Law, University of Pretoria, South Africa.

${ }^{2} 509$ US 579 (1993).

${ }^{3}$ The Kelly Fry[e] standard. See People v Kelly (1976) 17 Cal 3d 24 (California Supreme Court); Frye v United States (D C Cir 1923293 F 1013) (Court of Appeals, District of Columbia).

${ }^{4}$ Federal Rules of Evidence, Testimony by Expert Witnesses, 28 United States Code Annotated. At the time of the decision Rule 702 provided that if scientific, technical or other specialised knowledge will assist the trier of fact to understand the evidence, or to determine the a fact in issue, a witness qualified as an expert by knowledge, skill, experience, training, or education, may testify thereto in the form of an opinion or otherwise.

${ }^{5}$ At 89 and further.
} 
the expert's theory or technique can be, as has been, tested; 2) whether the theory or technique has been subjected to peer review and publication; 3 ) the known or potential rate of error; 4) the existence and maintenance of standards controlling the technique's operation; and 5) whether the theory or technique is generally accepted in the relevant scientific community. ${ }^{6}$ The government has the burden to establish the admissibility of the evidence on a balance of probabilities. ${ }^{7}$

Soon after this, in 1995, the Federal Bureau of Investigation (FBI) recognised the need for standardised procedures for fingerprint examiners. They held a meeting to discuss the development of consensus guidelines and from this meeting the Scientific Working Group on Friction Ridge Analysis, Study and Technology (SWGFAST) was born. SWGFAST developed guidelines for hiring, training and quality assurance. ${ }^{8}$

During 1997 the American Society of Crime Laboratory Directors requested the National Institute of Justice (NIJ) ${ }^{9}$ to convene a science team to identify the status and current need of the forensic sciences. This led to an NIJ publication titled 'Forensic Sciences: Review of Status and Needs' which included a section on latent print examinations. As far as fingerprint examinations were concerned the publication identified the "Validation of the Basis for Print (friction ridge) Individualization' and the 'Standardization of Comparison Criteria' as needs. ${ }^{10}$

In 1999 the United States Supreme Court in Kumho Tire Co Ltd v Carmichael ${ }^{11}$ confirmed the Daubert approach, but emphasised that the factors listed in Daubert may or may not be useful to determine the reliability of expert testimony, and that the Rule 702 enquiry is a flexible one. The circumstances of the case will determine whether a factor is pertinent. The court also extended Daubert's application to technical and other specialised knowledge.

At about the same time Byron Mitchell brought a motion to exclude the government's fingerprint identification evidence under the Daubert criteria prior to his retrial. ${ }^{12}$ The motion was denied by the district court and Mitchell was subsequently convicted. Approximately

\footnotetext{
6 At 593-4.

${ }^{7}$ Daubert (n 2) 593 n 10.

${ }^{8}$ National Institute of Justice, 'NIJ Solicitation: Forensic Friction Ridge (Fingerprint) Examination Validation Studies' (2000) at <https://www.ncjrs.gov/pdffiles1/nij/s000386.pdf> at II, accessed on 4 June 2012.

${ }^{9}$ An arm of the United States Department of Justice.

${ }^{10}$ See NIJ Solicitation (n 8).

11526 US 137, 150 (1999).

12 Previously Mitchell had been convicted but his conviction was set aside by the Court of Appeals due to an unrelated reason. See United States v Mitchell 145 F3d 572 (3d Cir 1998) (United States Court of Appeals, Third Circuit).
} 
three months after the verdict in May 2000 Mitchell brought a motion for a new trial due to the discovery of a solicitation by the NIJ titled 'Forensic Friction Ridge (Fingerprint) Examination Validation Studies'. The solicitation was issued by the NIJ a month after the Mitchell trial had been concluded in the district court in March 2000. The areas of research were 1) statistical validation of individuality in friction ridge analysis; 2) qualitative and quantitative aspects of friction ridge comparison; and 3) statistical validation of standard operating procedures for friction ridge (fingerprint) comparison. The district court denied the motion. The judgement of the district court was affirmed in the Court of Appeals. ${ }^{13}$

Soon thereafter, in December 2000, Rule 702 was amended to codify some of the aspects in Daubert and to give effect to Kumho Tire. No attempt was made to codify the specific factors in Daubert. ${ }^{14}$ In terms of the amended Rule $702:{ }^{15}$

A witness who is qualified as an expert by knowledge, skill, experience, training, or education may testify in the form of an opinion or otherwise if: (a) the expert's scientific, technical, or other specialized knowledge will help the trier of fact to understand the evidence or to determine a fact in issue; (b) the testimony is based on sufficient facts or data; (c) the testimony is the product of reliable principles and methods; and (d) the expert has reliable applied the principles and methods to the facts of the case.

In 2009 the 'National Research Council Committee on Identifying the Needs of the Forensic Sciences Community' in the United States of America, issued a report titled 'Strengthening Forensic Science in the United States: A path forward' (2009). ${ }^{16}$ The committee consisted of forensic scientists, statisticians, judges and lawyers. ${ }^{17}$ The report found that although fingerprint evidence has been used in court for 100 years, there is insufficient evidence to conclude that fingerprint comparison evidence is reliable. ${ }^{18}$

According to the report fingerprint examination is not supported by 'peer reviewed, published studies establishing [its] scientific basis and validity' and lacks 'rigorous protocols to guide ... [experts'] subjective assessments of matching characteristics' ${ }^{19}$ The report also indicates that the discipline lacks professional standards which make it difficult to 'determine

\footnotetext{
${ }^{13}$ United States of America v Byron Mitchell 365 F 3d 215 ( $3^{\text {rd }}$ Cir 2004) (United States Court of Appeals, Third Circuit).

${ }^{14}$ Ibid 234. See also Miami Criminal Lawyer Home, 'Federal Rules of Evidence: Rule 702' (2011) at $<$ http://www.joffelaw.com/federal-rules/evidence/Rule702.html> accessed on 8 June 2012.

${ }^{15}$ The quoted text is as it reads after the December 2011 amendment. Only the language changed in 2011 as part of a restyling of the evidence rules to make the text more understandable and to make the terminology and style consistent throughout the rules. See the Committee Notes on the 2011 amendment at the Miami Criminal Lawyer Home website ibid.

${ }^{16}$ United States of America v Raynard Council 777 F Supp 2d p 1007 (2011) (United States District Court, Eastern District of Virginia, Richmond Division). Hereafter referred to as 'the NRC report' or 'the report'.

${ }^{17}$ The People v Carl E Price 2011 WL 2043957 (cal App 2 Dist) item 18 (Court of Appeal, Second District, Division 4, California).

${ }^{18}$ Ibid.

${ }^{19}$ NRC report at 8.
} 
with adequate reliability that the finger that left an imperfect impression at the crime scene is the same finger that left an impression (with different imperfections) in the file of fingerprints. ${ }^{20}$ In concluding the report dismisses the contention by some examiners that friction ridge analysis is not subject to possible error. ${ }^{21}$

The report relied in part on the research of Dr JL Mnookin. ${ }^{22}$ Her research focuses on scientific evidence and in particular forensic scientific evidence and the validation of the scientific processes underlying forensic science evidence. ${ }^{23}$

In the wake of this report many motions were filed before trial in American courts to bar the government from presenting evidence that a fingerprint specialist had determined that one of the recovered 'latent' prints matched the 'known' fingerprint of the defendant. ${ }^{24}$ In other courts the defendant sought to introduce expert evidence at trial that fingerprint evidence was not reliable. ${ }^{25}$ In some courts the defendant tried to exclude the government's latent fingerprint evidence and to present the evidence of an expert challenging the reliability of fingerprint evidence. ${ }^{26}$ At the pre-trial hearings and at trial the defendants also crossexamined the government print examiners regarding the reliability of print examination.

A closer inspection reveals that the challenges were with regard to the reliability of fingerprint evidence in general, as well as the reliability of ACE-V, the preferred process or method of comparing the latent print to the known print in the United States of America. The challenges were therefore not only as to the reliability of the fingerprint comparison in the specific case.

In this article I investigate the grounds upon which these challenges were made and the position taken by the American courts. Because the challenges and the reasons given by the courts were very similar, I only discuss enough of the cases to give a clear picture of events. I also briefly discuss the fundamental test for the admission of expert evidence in jurisdictions with a strict system of evidence by using the United States of America and South Africa as examples, and consider whether the critique pointed out by the defendants in the

\footnotetext{
${ }^{20}$ Ibid at 43 .

${ }^{21}$ Ibid at 142 .

${ }^{22}$ She is a professor of law at the UCLA School of Law and holds a law degree from Yale University and a PhD in History and Social Study of Science and Technology from the Massachusetts Institute of Technology.

${ }^{23}$ Council (n 16) 1009.

${ }^{24}$ See eg United States of America v Robert Abdul Baines 573 F 3d 979 (10 ${ }^{\text {th }}$ Cir 2009) 981 (United States Court of Appeals, Tenth Circuit); Council (n 16); United States of America v David Brian Stone 2012 WL 219435 (E D Mich) (United States District Court, East Division, Michigan). See my explanation of the terms 'latent print' and 'known print' hereunder.

${ }^{25}$ See eg Price (n 17) item 18.

${ }^{26}$ See eg The People v Michael John Lugo 2009 WL 2025637 (Cal App 2 Dist) item 13 (Court of Appeal, second District, Division 5, California).
} 
American cases with regard to reliability are sufficiently penetrating to warrant the exclusion of fingerprint comparison evidence. In deciding whether the critique is sufficiently penetrating, I inter alia consider the practices and events with regard to fingerprint comparison in selected other jurisdictions, including that of prominent Commonwealth countries like England and Wales, Scotland and South Africa.

But, before doing this it is prudent to first explain certain terms with regard to fingerprint comparison, and to draw attention to the premises upon which fingerprint analysis is based.

\section{B Terminology and premises}

A 'fingerprint' can be defined as the 'ridged skin which appears on the palmar side of the hand for each of the fingers'. ${ }^{27}$ The ridge pattern can then be transferred to an object when it is touched or intentionally recorded on a fingerprint card.

A 'latent print' is a partial print like that found at a crime scene when something is touched, and is often invisible to the naked eye. ${ }^{28}$

A 'known print' is the print that is given intentionally to a law enforcement agency when one is for example arrested. The law enforcement agency or other agencies attempt to get the full print of each finger. Previously the prints were normally taken by putting ink on the fingers and then rolling the fingers on a paper card. In some jurisdictions certain agencies have adopted digital scanning techniques in place of the old method. ${ }^{29}$

'Fingerprint individualization' is a term used in latent fingerprint analysis which describes an identification that is based on absolute certainty by the examiner. ${ }^{30}$

'ACE-V' is the dominant mode of examination that is utilised in the United States of America. ${ }^{31}$ The letters of the acronym ACE-V refers to the four stages in the identification process namely 1) analysis; 2) comparison; 3) evaluation; and 4) verification. ${ }^{32}$

In the analysis stage the examiner looks at the latent print and the known print separately. The examiner makes an evaluation of the ridge flow $^{33}$ as well as the individual

\footnotetext{
${ }^{27}$ Baines (n 24) 982.

${ }^{28}$ Ibid. From the Latin word lateo, ‘to lie hidden'. See Mitchell (n 13) 220.

${ }^{29}$ Baines Ibid.

${ }^{30}$ The People v Kevin Caradine Jr, Not reported, case nr A121968, Court of Appeal, First District, Division 2 , California, Filed February 23, 2012 item III.

${ }^{31}$ See eg Lugo (n 26); Baines (n 24); United States of America v Ajmal A Aman 748 F Supp 2d 531 (E D Va 2010) (United States District Court, East Division, Virginia, Alexandria Division); Council (n 16).

${ }^{32}$ Baines (n 24) 983; Aman ibid 539.

${ }^{33}$ The direction of the friction ridges.
} 
ridges ${ }^{34}$ and the pores to evaluate the quality and quantity of the information at each level. If either the latent or known print is unsuitable for examination the analysis ends. If the prints are sufficiently clear the examiner records the various points at the three levels of specificity. At the first level the examiner may find a disparity that compels the conclusion that there cannot be a match. The examiner cannot confirm a match at the first level. ${ }^{35}$

In the second step a side by side comparison of the friction ridge characteristics of the latent and the known print is made. The examiner looks for similarities at the three levels between the two prints and reasons to exclude a match. If it appears possible that they might match the examiner goes on to the third stage. ${ }^{36}$

At the evaluation stage the examiner forms a conclusion about the prints. The examiner can conclude that they are a match ('individualization'), that they are not a match ('exclusion') or that the result is inconclusive. ${ }^{37}$ There are no set number of similarities that indicate a match. ${ }^{38}$ Both the quality and quantity of similarities allow for identification. ${ }^{39}$ The examiner will conclude there is a match if there are enough similar characteristics that make it impossible that another person's print would exhibit the same characteristics. ${ }^{40}$ Differences in fingerprints do not necessarily end analysis. The examiner must determine whether the dissimilarity is explainable given expected variations for example due to pressure differences, surface texture and print medium. ${ }^{41}$ However, a single unexplained dissimilarity will negate a match. $^{42}$

During the fourth stage a second examiner is provided the same prints and asked to verify the conclusion of the first examiner by using the first three stages of the ACE-V. The second examiner is aware of the first examiner's conclusion.

Fingerprint identification rests on two premises: That each individual's fingerprints are unique and that the unique pattern of the person's prints does not change over time. ${ }^{43}$

\section{The grounds against the reliability of fingerprint evidence and the position taken by the American courts}

\footnotetext{
${ }^{34}$ Including bifurcations, ridge endings and ridge dots.

${ }^{35}$ Baines (n 24) 983; Aman (n 31) 539; Council (n 16) 1008.

${ }^{36}$ Ibid.

37 Ibid

38 Aman (n 31) 539; Council (n 16) 1008.

${ }^{39}$ Ibid.

${ }^{40}$ Ibid.

${ }^{41}$ For example ink, blood or sweat.

42 Aman (n 31) 539; Council (n 16) 1008.

${ }^{43}$ Ibid.
} 
In United States of America $v$ Robert Abdul Baines ${ }^{44}$ the defendant in a pre-trial motion asked the court to exclude the testimony of the government fingerprint examiner. Baines argued that 1) the method of fingerprint analysis has not been tested; 2) there are no established error rates; 3) fingerprint examiners do not adhere to uniform objective standards; and 4) there is an absence of professional literature to support admission of the testimony of fingerprint examiners.

The district judge, while not directly addressing the concerns, concluded that the government examiner has shown on a balance of probabilities that the reasoning and methodology underlying fingerprint evidence is scientifically valid and was properly applied. She accordingly held that the evidence was shown to be relevant and reliable meeting the requirements of Rule $702 .^{45}$

With regard to the core of the defendant's argument that fingerprint examination rests substantially on the subjective interpretations of the examiner, the judge held that that argument went to the weight of the evidence and not its admissibility. She quoted the observation by the court in Daubert that '[v]igorous cross-examination, presentation of contrary evidence and careful instruction on the burden of proof are the traditional and appropriate means of attacking shaky but admissible evidence". ${ }^{4}$

In the Court of Appeals the court dealt with all the Daubert factors. With regard to the first factor that the technique can be, as has been tested, the court found that although the record did not show that the testing would meet all the standards of science, the technique has been subject to testing in the world of criminal investigation and other practical applications. In law enforcement, fingerprint identification has been utilised by agencies all over the world for over a hundred years and the examiners are subject to demanding training and on-going proficiency examinations. Although the proficiency exams had been criticized on several grounds the court saw no basis on the record to totally disregard the proficiency tests. The court found that the first factor weighed somewhat in favour of admissibility, although not powerfully. $^{47}$

With regard to the second factor, peer review and publication, the court found the defendant's argument that the verification stage of the ACE-V process is not the independent

\footnotetext{
${ }^{44}$ (n 24) 981, 982.

45 Ibid at 985.

${ }^{46}$ Daubert (n 2) 596.

${ }^{47}$ At 990.
} 
peer review of true science convincing. In accordance with this the court found that the second factor did not favour admissibility. ${ }^{48}$

The third factor is the known or potential error rate of procedure. The court found that the evidence of error rate on record strongly support a decision to admit the evidence of the fingerprint examiner. ${ }^{49}$

The fourth factor is the existence and maintenance of standards controlling the process. The court indicated that it could find very little evidence of standards that guide and limit the analyst in the execution of his duties. Critical steps in the process depended on the subjective judgement of the analyst. However, the court added that subjectivity does not preclude a finding of reliability. The court assumed for argument purposes that this factor did not support admission. ${ }^{50}$

The fifth factor is whether the technique has gained general acceptance in the relevant scientific or expert community. The defendant contended that fingerprint analysis has not been accepted in any unbiased scientific or technical community. The court while acknowledging that unbiased experts would carry greater weight held that the overwhelming acceptance by other experts in the field should also be considered. ${ }^{51}$

The court found that on a whole, fingerprint analysis evidence is suitably reliable for admission. $^{52}$

In The People v Michael John $\operatorname{Lugo}^{53}$ the defendant tried, also by way of a motion before trial, to exclude the government's latent fingerprint evidence based on Daubert. Counsel argued that there was an absence of scientific testing with regard to fingerprint comparison evidence. She noted that there had been no studies to determine the probability of two different people having a number of fingerprint characteristics in common. With regard to ACE-V in particular she argued that it has never been scientifically tested for reliability, and that the authentication process is not a blind procedure.

In denying the motion the trial court held that Daubert had not been accepted by the California Supreme Court and that the Kelly Fry $[e]^{54}$ standard for admitting the results of new scientific techniques remains the California standard. The court also indicated that the

\footnotetext{
48 Ibid.

${ }^{49}$ At 991 . The government examiner testified to an error rate of one per every eleven million. This evidence was not challenged.

${ }^{50}$ At 991.

51 At 992 .

52 Ibid.

${ }^{53}$ (n 26) item 13.

54 See (n 3).
} 
California Supreme Court has rejected challenges to the admissibility of expert fingerprint testimony on the basis that it fails to meet the appropriate standards. The court also held that fingerprint evidence has been accepted for identification purposes in the United States for about a century and it is the strongest evidence of identity. ${ }^{55}$

The district court indicated that the defendant had the following options: He could 1) call his own expert to testify on the reliability of the subject matter, as a criminalist; 2) get his own expert to compare the prints and testify that they are not a match; and 3) cross-examine the witness to test the reliability of the match. ${ }^{56}$

The Court of Appeal agreed with the trial judge indicating that the type of fingerprint analysis involved in the case evidence was not subject to challenge. The court held that the jury could make its own comparisons between the latent and known print. ${ }^{57}$

The premise that fingerprints are unique was also challenged during crossexamination of government fingerprint examiners. In one such challenge the examiner was asked whether any scientific data supported the assertion that each individual's fingerprints are unique. She replied that the medical research, the observations, the statistics modelling and the daily AFIS searching supported the theory that fingerprints are unique and that it can be used for identification. ${ }^{58}$

When asked who supported the assertion that individualised fingerprint identification is accurate she indicated that the 'biological uniqueness' and permanency has been accepted by society for over a hundred years. She added that there is no any scientific proof that a fingerprint is unique because the latent print cannot be compared to everybody's fingerprints in the world. ${ }^{59}$ 'But since it's accepted in society and it's supported by us, ... it is used as a tool in identification'. ${ }^{60}$ She also indicated that she had never heard of a study that found that fingerprints from two different people were the same.

In United States of America $v$ David Brian Stone ${ }^{61}$ the defendants in another pre-trial motion asked the court to exclude the testimony of the government fingerprint examiner. They argued that the poor quality of latent fingerprints created problems in the identification process. They also relied on the 2009 Report and argued that application of the Daubert factors revealed that fingerprint identification evidence was unreliable and inadmissible.

\footnotetext{
${ }^{55}$ At item 13.

${ }^{56}$ Ibid.

${ }^{57}$ At item 15.

${ }^{58}$ Price (n 17) item 17.

${ }^{59}$ Ibid item 17 and 18.

${ }^{60}$ Ibid item 18.

${ }^{61}$ (n 24) item 3.
} 
The trial court pointed out that defendants did not challenge the proposed testimony of the government examiner based on his individual reasoning or testing methodology. Defendants instead attacked identification evidence in general, calling it unreliable. The court citing United States v Byron Mitchell ${ }^{62}$ held that such an unspecified attack on a wellestablished area of expertise did not warrant a Daubert hearing. The court also referred to Crisp $^{63}$ where the Fourth Circuit held that ' $[\mathrm{u}]$ nder Daubert, a trial judge need not expend scarce judicial resources re-examining a familiar form of expertise every time opinion evidence is offered'. ${ }^{64}$ Anyhow, the court was not convinced that the Report provided a sufficient basis to exclude the fingerprint evidence from trial.

The Court of Appeal found no basis to depart from the findings in numerous other courts that latent fingerprint examination was reliable under the five-pronged test developed in Daubert. The court held that criticisms with regard to ACE-V and the risk of errors go to the weight of the evidence and can be contested through cross-examination and competing evidence. $^{65}$

As far as the giving of evidence to prove the unreliability of fingerprint evidence is concerned, the challenge predominantly came by way of the evidence of Professor Simon Cole. ${ }^{66}$ He testified in approximately seventeen admissibility hearings and nine trials across the United States of America. ${ }^{67}$

Cole's challenge to the reliability of fingerprint evidence was based upon several factors. The first is that he has found no study validating the reliability of fingerprint individualisation. ${ }^{68}$ Because there is no scientific data that supports the reliability of latent print individualisation, such a claim cannot be made by fingerprint examiners. ${ }^{69}$

\footnotetext{
${ }^{62}$ (n 13) citing Kumho Tire (n 11) 152.

${ }^{63} 324$ F 3d at 268 (2003) (United States Court of Appeals, Fourt Circuit). In Crisp the court acknowledged the need for further research into fingerprint analysis but indicated that that did not mean that the drastic step must be taken to exclude a long accepted and 'bedrock forensic identifier'.

${ }^{64}$ See also United States v Cooper 91 F Supp 2d 79, 82 (DDC 2000) (United States District Court, District of Columbia).

${ }^{65}$ Item 4. See also United States v George 363 F 3d 666, 673 ( $7^{\text {th }}$ Cir 2004) (United States Court of Appeals, seventh circuit).

${ }^{66} \mathrm{PhD}$. He received his doctorate in science and technology studies 'which uses the tools of the social scienceshistory, sociology, anthropology, political science-to study the social phenomena of our science and technology.' See The People v Daniel Gonzalez, case nr E052000, Court of Appeal, Fourth District, Division 2, California, Filed 22, 2012. Cole is a tenured Professor at the University of California, Irvine and has authored a book Suspect Identities: A History of Fingerprinting and Criminal Identification (Harvard University Press 2001) and many articles on the reliability of latent fingerprint individualisation. He has also lectured extensively on the subject.

${ }^{67}$ See for example Lugo (n 26); Price (n 17); Gonzalez ibid.

${ }^{68}$ See for example Price ibid 18; Gonzalez ibid item 1.

${ }^{69}$ Caradine Jr (n 30) item III.
} 
It is not clear from most of the case reports whether Professor Cole also contested the fact that fingerprints were unique and permanent. However, in one such admissibility hearing Cole agreed that all complete $e^{70}$ fingerprints were unique. ${ }^{71}$ Still, he held that this does not prove accuracy and mistakes can be made. With latent prints only partial prints are collected. He indicated that there was no standardised threshold as to how much consistent detail between the latent print and the known print is needed to reach a conclusion of identification. $\mathrm{He}$ emphasised that the claim by fingerprint examiners that they can make 'individualizations' is not supported by the relevant scientific community. With 'the relevant scientific community' Cole meant some thirty scientists and scholars who published on the topic.

He also relied on the findings of the National Research Council Committee in the 2009 report supra. Cole considered the report to be a statement of the relevant scientific community.

Cole was able to document twenty two misidentifications in the United States of America and the United Kingdom in 2005, and a subsequent study revealed between thirty and forty misidentifications. ${ }^{72}$

In The People v Daniel Gonzalez ${ }^{73}$ the trial court ruled that Professor Cole could not testify at trial because his proposed testimony would not assist the jurors. The court held that what Professor Cole's testimony in essence said was that mistakes can be made, and you do not need an expert to say that someone could have made a mistake. The court did not think that this kind of evidence would assist the jury. The court indicated that one could crossexamine the people who testify, and bring one's own expert to testify on the issues.

The Court of Appeal found that the trial court did not abuse it's discretion in precluding Professor Cole's testimony. The relevant issue was whether the prints found belonged to the defendant. Professor Cole was not qualified to lift or compare prints and could not, and did not offer to evaluate the officer's work at the scene, or the comparison made by the examiners. ${ }^{74}$

The Court of Appeal also held that fingerprint analysis was not new to science or the law. The defendant at most offered testimony criticising the lack of uniformity or set standards within the fingerprint community. He argued that mistakes do occur. However, he

\footnotetext{
${ }^{70}$ My emphasis.

${ }^{71}$ Caradine $\mathrm{Jr}$ (n 30) item III.

${ }^{72}$ Gonzalez (n 66) item II.

${ }^{73}$ Ibid.

${ }^{74}$ Ibid.
} 
did not show that the reliability of fingerprint identification techniques is no longer generally accepted in that community. Referring to the decision in the California Supreme Court in People v Farnam ${ }^{75}$ with regard to a similar challenge concerning the state's computerised fingerprint matching system, the court held that the jury could make its own comparisons between the latent prints and defendant's fingerprints.

In The People $v$ Kevin Caradine $\mathrm{Jr}^{76}$ the trial court in denying the motion for Professor Cole to testify at trial added that it would be undue consumption of time to allow the evidence. The probative value is clearly and substantially outweighed by the prejudice of allowing the evidence as not much probative value can be seen in this anecdotal information. This view was also taken by the Court of Appeal.

The Court of Appeal in addition held that Professor Cole has no training or expertise in fingerprint analysis but is merely relating a collection of things he has read. The court concluded that someone who has studied and written on the subject of fingerprint examination, but had never himself studied fingerprints, did not qualify as an expert for purposes of Rule $702 .^{77}$

In United States of America $v$ Raynard Council, ${ }^{78}$ the defendant offered the testimony of Professor Mnookin ${ }^{79}$ at the pre-trial admissibility hearing to contest the reliability of ACE$\mathrm{V}$ as a method to determine a fingerprint match.

Professor Mnookin questioned the validity of ACE-V as a scientific method. According to her, ACE-V did not describe a scientific process. It rather helped examiners to look carefully. She argued that the different stages lacked content making it difficult for examiners to make difficult decisions at each stage. She explained that ACE-V had no objective criteria to determine whether a print is fit for analysis and comparison. ACE-V does not explain how to make the determination or how many characteristics is enough to allow an examiner to make that judgement. That decision therefore relied almost entirely on the experience and intuition of the examiner.

The district court in allowing the evidence of the government examiner held that Daubert required the court to ensure that an expert witness's examination was reliable. However, Daubert, does not 'demand of expert testimony such an extremely high degree of

\footnotetext{
75 (2002) $28 \mathrm{Cal} 4^{\text {th }} 107,160$.

76 (n 30) item III.

77 Ibid.

${ }^{78}$ (n 16) 1009.

${ }^{79}$ See (n 22).
} 
intellectual purity that an underlying procedure must be truly scientific in an intellectual, abstract sense in order to be admitted. ${ }^{80}$

The court held that the ACE-V method of examination was widely accepted in the relevant field and the examiner applied widely recognized standards maintained by fingerprint examiners. Even if the ACE-V method allowed some marginal discretion on the part of the examiner, the examiner's subjective judgments were cordoned off by the objective standards applied by virtually the entire community of friction ridge examiners.

However, the court did agree that the evidence of Prof Mnookin and the NRC report pointed out areas in which standards governing friction ridge analysis should continue to develop and that other courts have recognised that friction ridge analysis has not attained the status of scientific law. ${ }^{81}$ The government examiners and Prof Mnookin also agreed that more testing should be done to determine the reliability of friction ridge analysis and that the critics of ridge analysis suggest an error rate of three percent. Yet, the court held that these and other remaining objections about standards go to the weight of the government expert's evidence, rather than its admissibility. ${ }^{82}$ The court accordingly found that the method of examination was sufficiently reliable for admission as expert testimony.

\section{Discussion}

The strict system of evidence is to a large extent a phenomenon associated with adversarial systems of evidence which have experienced extensive lay participation in the adjudication of disputes, like for example, in the United States of America. The principal idea is that lay adjudicators need to be guided by rules of admissibility in the adjudication of facts. ${ }^{83}$

To the Anglo-American lawyer the admissibility of evidence is for the biggest part a question of law. This is also true for other common law jurisdictions like South Africa where the jury system has been abolished approximately forty five years ago, and the idea that a professional adjudicator should not be hampered by artificial rules of admissibility has not gained ground. ${ }^{84}$

\footnotetext{
${ }^{80}$ At 1012, quoting Baines (n 24) 981, 989.

${ }^{81}$ At 1013. See for example Baines ibid 990; Aman (n 31) 539-543.

${ }^{82}$ At $1012,1013$.

${ }^{83}$ In the inquisitorial jurisdictions where there was never lay participation in the adjudication process, it is accepted that a professional adjudicator should not be hampered by artificial rules relating to the exclusion of evidence.

${ }^{84}$ This can perhaps be justified by the use of lay assessors in the lower and high courts. They can perhaps be compared to jurors as the assessors are predominantly finders of fact, and not legal issues.
} 
In these systems the fundamental test for the admission of expert evidence is relevance. Under Rule 702 the evidence is relevant if the evidence 'will help the trier of fact to understand the evidence or to determine a fact in issue'. The expert is accordingly allowed to give non-opinion and opinion evidence. With non-opinion evidence the expert is allowed to give an exposition of scientific or other principles leaving the trier of fact to apply them to the case.

Under South African law the court must be satisfied that a) the witness has specialist knowledge, training, skill or experience and can because of these attributes or qualities, assist the court in deciding the issues; ${ }^{85}$ b) the witness is an expert for which he is called upon to express an opinion; ${ }^{86}$ and c) the witness does not or will not express an opinion on hypothetical facts. ${ }^{87}$

Both systems therefore allow for expert opinion evidence. If the issue is of such a nature that the witness is in a better position than the court to form an opinion, that opinion will be admissible to assist the trier of fact to decide the case. ${ }^{88}$

When it is decided whether expert evidence is admissible, reliability plays an important role. Evidence cannot prove or disprove a fact in dispute if the evidence is not at an acceptable level of reliability. Under Rule 702 the evidence must as a result of the influence of Daubert be the product of reliable principles and methods, and the expert must have reliably applied the principles and methods to the facts of the case. In Daubert ${ }^{89}$ the court also identified several factors in a flexible test that may be relevant in the reliability enquiry.

In Mohamed $v$ Shaik ${ }^{90}$ the South African high court held that the court must decide whether the expert has the necessary qualifications and experience to enable him to express reliable opinions. In Ruto Flour Mills Ltd v Adelson (1), ${ }^{91}$ the high court overruled the objection to an experts' opinion inter alia because there was nothing objectionable regarding the reliability of the evidence. Formal qualifications are not always needed. The practical

\footnotetext{
${ }^{85}$ Ruto Flour Mills Ltd v Adelson (1) 1958 (4) SA 235 (T). See also Mkize v Lourens 2003 (3) SA 292 (T).

${ }^{86}$ Goliath v Fedgen Insurance Company Ltd 1994 (2) PH F31 (E) 83.

${ }^{87}$ Facts that have no bearing on the case or that cannot be reconciled with all the other evidence in the case. See $S$ v Mkohle 1990 (1) SACR 95 (A) 100d; Sv Mponda 2007 (2) SACR 245 (C) [49].

${ }^{88}$ Pamela Schwikkard \& Steph Van der Merwe Principles of Evidence (3 ${ }^{\text {rd }}$ ed, Juta 2009) 83 and further.

${ }^{89} 509$ US 579 (1993) 593-4.

$901978(4)$ SA $523(\mathrm{~N})$.

911958 (4) SA 235 (T).
} 
experience of a witness may be decisive. ${ }^{92}$ The party that seeks to adduce the evidence must satisfy the court that the evidence is not irrelevant. ${ }^{93}$

It now remains to consider whether the critique pointed out by the defendants in the American cases with regard to reliability are sufficiently penetrating to warrant the exclusion of fingerprint comparison evidence.

The American courts themselves, even while holding that latent fingerprint evidence bears sufficient indicia of reliability under Daubert to overcome the Rule 702 hurdle, expressed some concern regarding the ACE-V method of fingerprint comparison and the reliability factors in Daubert. It can also be argued that many of the courts placed too much emphasis on the general acceptance of fingerprint evidence and that they effectively applied the Fry-Kelly standard. ${ }^{94}$ If due weight had been afforded to the other factors, the result may well have been more damning of fingerprint comparison evidence. It is also reasonable to surmise that the courts had been very aware of the catastrophic consequences if fingerprint comparison evidence was found to be unreliable. Agencies would lose a very valuable, if not irreplaceable forensic tool in fighting crime, and a hundred years of convictions, where fingerprints played a role, would be cast into doubt.

Yet, the purpose is not to give an opinion whether fingerprint comparison evidence should have been excluded under Daubert, but to give an opinion whether there is reason to conclude from the happenings in the American courts, that fingerprint comparison evidence is not reliable enough to be presented as evidence in court. In this quest the Daubert factors remain of assistance.

As far as the challenge to the premise that each individual's fingerprints are unique is concerned, the print examiners in government agencies strongly argued that the facts supported the uniqueness. They argued that medical research, observations, daily searches of fingerprint databases over approximately a hundred years and surveys and statistical studies conducted within the fingerprint communities, supported the contention that each individual's complete and partial fingerprints are unique. ${ }^{95}$ They also indicated that there was no evidence

\footnotetext{
${ }^{92} S$ v Mlimo 2008 (2) SACR 48 (SCA).

${ }^{93}$ Pamela Schwikkard \& Steph Van der Merwe (n 88) 95.

${ }^{94}$ See (n 3). Under Fry-Kelly general acceptance in the relevant scientific community allowed admission of the evidence. In terms of Daubert general acceptance in the relevant scientific community is but one of five suggested factors in a non-exhaustive list of factors to be weighed.

${ }^{95}$ In one survey the FBI polled law enforcement agencies in all fifty states as well as the District of Columbia, Canada and the United Kingdom and found that none of these agencies had ever found two people with the same fingerprints and that none of the agencies had ever matched a latent print with two different people. The FBI conducted the survey for purposes of the Daubert hearing in Mitchell (n 13). See also Baines (n 24) 987.
} 
that any study had ever found that a fingerprint of two different people were the same. ${ }^{96}$ In one admissibility hearing Professor Cole also agreed that all complete fingerprints were unique. $^{97}$

However, the government surveys and studies have not been without criticism. In one such study commissioned by the FBI in 2000, Lockheed Martin extracted fifty thousand prints from the FBI database and compared it with itself and every other print in the database. ${ }^{98}$ In a second trial it was determined that the average latent print was about twenty two percent of the image of a known print. About twenty percent of the data from each latent print was extracted and compared with the entire print from which it was extracted, as well as every other print in the database. The FBI's Automated Fingerprint Identification System (AFIS) that went live in 1999 was used to make the comparisons. ${ }^{99}$ The study concluded that there was almost no chance of finding two persons with the same print even when based on partial prints. ${ }^{100}$

In 2002 Epstein severely criticised these trials in a published paper as follows: ${ }^{101}$ The study had not been published two years after its completion, undoubtedly because in fingerprint identification, the concept of 'identical' is meaningless. The Lockheed representative acknowledged that even if the same finger is rolled in ink, the prints will not be the same due to the various distortions that occur in the rolling process. This was proved by the experiments. Included in the fifty thousand prints there were more than one fingerprint of the same fingers of individuals that were apparently fingerprinted twice by the FBI. The scores that were generated when the prints of the same finger were compared were significantly lower than when the fingerprint was compared to itself. In some instances the scores that were generated when the different prints of the same finger were compared were so low that it fell well within the scores generated when two different fingers were compared. Some fingerprints of different fingers accordingly had greater similarity than prints of the same finger. Accordingly two fingerprints of the same finger would not meet the definition of 'identical' that Lockheed established through the methodology of comparing a fingerprint

\footnotetext{
${ }^{96}$ See eg Price (n 17) item 1.

${ }^{97}$ Caradine Jr (n 30) item III.

98 The study was commissioned by the FBI. The study was also specifically done for purposes of the Daubert hearing in Mitchell (n 13). The study was also referred to by the government examiner and accepted as proof of reliability of fingerprint comparison by the district and Court of Appeals in Baines (n 24) 987.

99 See Elizabeth Montalbano, 'Lockheed Enhances FBI Fingerprinting System' (2011) at $<$ http://www.informationweek.com/news/government/security/229401509> accessed on 6 June 2012.

${ }^{100}$ Baines (n 24) 987; Rob Epstein 'Fingerprints meet Daubert: The Myth of Fingerprint "Science" is Revealed' (2002) 75 California Law Review 605 629, 630.

${ }^{101}$ Rob Epstein ibid.
} 
with itself. The tests therefore established nothing with regard to the uniqueness of fingerprints.

If the facts in Epstein's critique are correct, this study is not helpful in showing that fingerprints are unique. Unintentionally, it rather casts doubt on the accurateness of prints that have been rolled in ink. However, this does not mean that fingerprints are not unique. It was just not proven in the study.

It is certainly also not ideal that all the surveys and studies referred to in the cases were conducted either within government fingerprint communities who's livelihoods depend on the fact that fingerprints are unique, or by Lockheed who manufactures, sells and supports the fingerprint identification system utilised by the FBI. ${ }^{102}$

It has furthermore been 15 years since the NIJ had identified the validation of the basis of fingerprint individualisation as a need (1997), and 12 years since the NIJ issued a solicitation to research the 'statistical validation of individuality in friction ridge analysis' (2000). ${ }^{103}$ Still, there is no objective peer-reviewed study supportive of the uniqueness of fingerprints.

In 2012 the Report of the Expert Working Group on Human Factors in Latent Print Analysis titled 'Latent Print Examination and Human Factors: Improving the Practice through a Systems Approach'(2012) ${ }^{104}$ confirmed that a claim that a latent fingerprint belonged to one finger of a specific individual to the exclusion of every other in the world (individualisation) could as yet not be adequately supported by fundamental research, and that it was impossible to validate solely on the basis of experience. ${ }^{105}$

The fact that a research driven society like the United States of America has not been able to prove uniqueness is worrying and leads one to think that it cannot be proven. Yet, the only individuals that do comparisons are fingerprint examiners and they have been in agreement across the world for approximately a hundred years that complete and partial fingerprints are unique. The individuals that question whether fingerprints are unique have never lifted or compared prints, neither are they qualified to do so. I accordingly submit that the fact that there has never been an objective scientific peer reviewed study to determine the

\footnotetext{
${ }^{102}$ See Elizabeth Montalbano (n 99).

103 See the 'Introduction and Background'.

${ }^{104}$ Ch 10 'Summary and Recommendations'. The report was produced by the NIJ in collaboration with the Law Enforcement Standards Office in the US Department of Commerce's National Institute of Standards and Technology.

${ }^{105}$ See also Michael Saks and Jonathan Koehler, 'The Individualization Fallacy in Forensic Science Evidence' (2008) 61 Vanderbilt L Rev 199.
} 
probability that two different people may have the same fingerprint, or a number of similar fingerprint characteristics, ${ }^{106}$ is not enough to disturb the premise that fingerprints are unique.

However, until the uniqueness claim can be backed by fundamental research it would not be appropriate to make such a claim. ${ }^{107}$ Models to allow and support an estimate of the probability of a print being unique are currently being developed. ${ }^{108}$ Once the models have been developed it would be more precise to provide such estimate.

Of much more concern is the process by which comparisons are made. As far as fingerprinting in the United States of America is concerned, the FBI had already recognised the need for standardised procedures in 1995. In 1997 the NIJ recognised the need for the standardisation of comparison criteria. In 2009 the National Research Committee on Identifying the Needs of the Forensic Sciences Community severely criticized fingerprint examination, saying, inter alia, that it lacks rigorous protocols to guide the experts' subjective assessments of matching characteristics, and that the discipline lacks professional standards. $^{109}$

Yet, the ACE-V protocols still show a glaring lack of standards or control and the process is still very much a subjective one. There are no objective criteria guiding the examiner at any of the three levels of detail to assist the examiner to determine whether the latent and known print is suitable for analysis and comparison. At the evaluation stage, there is no set number of similarities that indicate a match. Both the quality and quantity of similarities allow for identification. There is no standardized threshold as to how much consistent detail between the latent print and the known print is needed to reach a conclusion of identification. The examiner will conclude there is a match if there are enough similar characteristics that make it impossible that another person's print would exhibit the same characteristics. Differences in fingerprints do not necessarily end the analysis. The examiner must determine whether the dissimilarity is explainable given expected variations for example due to pressure differences, surface texture and print medium. Only if a difference is not explainable, there will not be a match.

Clearly the outcome of the investigation depends on the training, experience and ability of the examiner. In 1995 the Collaborative Testing Service (CTS) administered a proficiency test designed by the International Association for Identification (IAI) to one

\footnotetext{
${ }^{106}$ See Lugo (n 26) item 13.

107 See also Michael Saks and Jonathan Koehler (n 105); Report of the Expert Working group (n 104) Ch 10 'Summary and Recommendations'.

${ }^{108}$ The Report of the Expert Working Group ibid par 4.3.

${ }^{109}$ See the 'Introduction and Background'.
} 
hundred and fifty six print examiners in the United States. In the test seven latent prints and four suspect cards with ten fingerprints were given to the examiners. Only sixty eight (44\%) correctly identified all seven latent prints by way of the ACE-V protocols. Forty eight incorrect identifications were made. ${ }^{110}$ The outcome led to shock and disbelief in the forensic community. ${ }^{111}$

The subjectivity was also illustrated in United States $v$ Mitchell. ${ }^{112}$ In Mitchell two FBI fingerprint examiners found that the left and right thumbprint that was left on the getaway car matched Mitchells' left and right thumbprint. The prosecution sent the two latent prints and Mitchells' ten print card to fifty three law enforcement agencies for identification. Twenty seven percent of the thirty four agencies that replied ${ }^{113}$ did not match one or both of the prints to Mitchell. ${ }^{114}$

More recently, in December 2011, The Fingerprint Inquiry, Scotland ${ }^{115}$ confirmed that findings were based on personal opinion and that this opinion was influenced by 1) the quality of the materials that were examined;2) the examiners' ability to observe detail in prints reliably; 3) the subjective interpretation of observed characteristics; 4) 'the cogency of explanations for any differences'; and 5) the subjective view of sufficient characteristics for a match. The Inquiry recommended that examiners should cease to make an identification or exclusion on a hundred percent certainty, or on any premise that fingerprint evidence is infallible. ${ }^{116}$

In 2012 The Expert Working Group ${ }^{117}$ reaffirmed that from the first to the last step in the identification or exclusion process examiners were engaged in interpretations based on professional knowledge and experience, rather than on formal decision thresholds or statistical models.

It appears that there is a need for objective indicators and standards. However, this is easier said than done. In the vast majority of other jurisdictions a minimum amount of ridge similarities is required to make a match. In South Africa seven points of similarity is

\footnotetext{
${ }^{110}$ Sandy Zabell, 'Fingerprint Evidence' (Spring 2005) 13 Journal of Law and Policy, 143.

${ }^{111}$ David Grieve, the editor of the 'Journal of Forensic Identification' described the outcome of the CTS proficiency test among the forensic community as ranging from shock to disbelief. See Wikipedia. 'Fingerprint' (2012) at $<$ http://en.wikipedia.org/wiki/Handprint $>$ accessed on 8 June 2012. It may even be argued that under normal circumstances the results would probably be worse. When people know that their performance is monitored it changes their behaviour and performance for the better.

112 (n 13).

11313 Examiners from nine states.

114 Mitchell (n 13) 231. See also Rob Epstein (n 100) 629.

115 'The Fingerprint Report' (2011) at $<$ http://www.thefinger printinquiry scotland. org.uk/inquiry/ CCC First Page.jsp> 'Key Recommendations'> ch 42 accessed on 24 August 2012.

116 Ibid.

${ }^{117}$ See (n 104) ch 10 'Summary and Recommendations'.
} 
required. ${ }^{118}$ In Australia a minimum of twelve is required. In Italy and France sixteen points of similarity is needed and in Brazil and Argentina thirty is needed to make a match. Historically most of the countries have required between eight and sixteen matching characteristics. $^{119}$

Yet, there are still other countries apart from the United States of America where no minimum amount of similar characteristics is required for an identification. Notable examples of these countries are Canada, England and Wales and Scotland. ${ }^{120}$ The example of England and Wales and Scotland is especially interesting. In England and Wales there were originally no standards, but once twelve similar characteristics were identified, it proved a match beyond all doubt. From 1924 the Metropolitan Police required sixteen similarities to prove a match. Not all police agencies accepted the sixteen point requirement. In 1953 a national standard of sixteen characteristics was adopted. ${ }^{121}$ In 2001 the numerical standard was abolished because a study by Evett and Williams had found that there was no statistical, logical or scientific basis for the use of a numeric standard. ${ }^{122}$ In Scotland the historical outline is similar to that of England and Wales. ${ }^{123}$ However, it was not until September 2006 that the requirement for a minimum set of characteristics was abandoned. ${ }^{124}$

It is apparent from the examples that I have referred to that the requirement for an identification ranges from no minimum amount of similarities, to thirty similarities. Even if it is decided that a minimum standard should be set, it is impossible in the absence of a statistical, logical or scientific basis, to say what that amount should be. To set an average or even a 'safe' standard is unacceptable. If a match is achieved in this way, a presumed but false certainty will be presented for the truth.

In light of this shortcoming, and due to the uncertainty brought about by the subjectivity of the process, it is crucially important that an identification be reviewed by at least one independent expert before it is presented as evidence. An expert is only helpful if he is objective. To be able to be objective, he must be neutral. The opinion of an expert is of little value if he is partisan and consistently asserts the cause of the party who calls him.

\footnotetext{
${ }^{118}$ S v Kimimbi 1963 (3) SA 250 (C); Sv Nala 1965 (4) SA 360 (A).

119 Lirieka Meintjies-van der Walt, 'Fingerprint evidence: probing myth and reality' (2006) South African Journal of Criminal Justice 2, 152166.

${ }^{120}$ Ibid. Also See Ian Evett and Ray Williams, 'A Review of the Sixteen Point Fingerprint Standards in England and Wales' (1996) 46 Journal of Forensic Identification 49; The Fingerprint Enquiry Report (n 115) ch 33.

${ }^{121} R v$ Buckley (1999) 163 JP 561; Ian Evett and Ray Williams ibid.

${ }^{122}$ The study was commissioned by the Association of Chief Police Officers. See ibid.

123 The Fingerprint Inquiry Report (n 115) par 32.2.

${ }^{124}$ Ibid par 33.1.
} 
In some countries, for example South Africa, an examination by a second examiner is not required. However, it has been customary for some time in South Africa for the same examiner to take the fingerprint of the accused on the morning of the trial, and to once again compare it with the print found at the scene. ${ }^{125}$ This is not satisfactory as the same inadequacies may lead to the same mistakes and the examiner is not neutral. He asserts the cause of the prosecution.

In the United States of America an identification is verified by one other examiner, and in England and Wales the identification is verified by two other examiners. ${ }^{126}$ In Scotland a suspect identification is verified by a minimum of two other examiners, ${ }^{127}$ and in the Netherlands verification of an ordinary print is done by one other examiner. ${ }^{128}$ All the examiners are from the same agency with knowledge of the prior conclusion(s).

This is also not satisfactory. The later examiner is influenced by the earlier conclusion(s) and has an interest therein that the agency prosecutes crime effectively. The later examiner may well also be influenced by the earlier examiner(s) and other members of the agency on a personal level, as well as other facts of the case leading the examiner to believe that the owner of the prints is guilty.

This viewpoint has been confirmed by studies examining whether inherent psychological and cognitive mechanisms predispose fingerprint examiners to errors. In one such study six highly experienced and trained fingerprint experts from across the world, ${ }^{129}$ all of whom had done proficiency testing and had been certified by a nationally recognised independent authority, participated. ${ }^{130}$ The prints were all from real crime scenes and were all presented to the participants in their original format for comparison against ten print cards. All the prints were obtained from the archives and had been evaluated some years before by the same experts. Half of the prints provided no contextual information and were used as controls. The other half provided routine, day-to-day contextually biasing information for

\footnotetext{
${ }^{125}$ Cerita Joubert (ed) applied law: For police Officials (Juta 2001).

${ }^{126}$ See $R v$ Smith [2011] EWCA Crim 1296 (case nr 2009/03393/C1); ch 6.

${ }^{127}$ The Fingerprint Inquiry Report (n 115) par 36.46.

128 The Fingerprint Inquiry Report ibid par 36.48. Two independent experts are only asked to verify the identification in a multiple procedure once the print is deemed to be a 'complex mark' for example where the examiners differ in their conclusions, the print is borderline in quality or when the examiner finds anything questionable. It is reasonable to surmise that the majority of prints will not be screened by an independent examiner before it is presented in court. The examiners may in the first place not disagree in their conclusions because of the influence of an earlier conclusion or the other influences mentioned above. The question whether a print is borderline or anything is questionable may well also be influenced by the necessity or desire to keep bureaucratic requirements to a minimum so as not to drive up costs and negatively impact on the speed of the prosecution. The print may even wrongly be denied independent scrutiny due to incompetence or inexperience.

${ }_{129}$ Including the United States of America, the United Kingdom, Israel, the Netherlands and Australia.

${ }^{130}$ Itiel Dror and David Charlton 'Why Experts Make Mistakes' (2006) 56(4) Journal of Forensic Identification 600 .
} 
example that the prints were 'an individualization', or that the suspect was in police custody at the time of the crime. Both the control prints and those with contextually biasing information included prints where an identification had previously been made, and where a match was excluded. The trial showed that the experts changed $16.6 \%$ of their earlier decisions due to biasing context. The trial also showed that the psychological and cognitive vulnerabilities were more pronounced in difficult cases.

In another study latent prints and cards that were previously positively matched were presented to the same examiners for comparison. ${ }^{131}$ This time it was suggested that there was no match and that the suspects could not be identified. Four of the five participants changed their decision. Three of the four judged the prints as definitely not a match and one decided that there was not enough information to make a match. ${ }^{132}$

The prosecution of Ms Shirley McKie ${ }^{133}$ in Scotland ${ }^{134}$ and the recent English case of $R v$ Smith $^{135}$ are real life examples of why an examiner from the same agency should not review an identification.

In the first example Ms McKie ${ }^{136}$ was initially part of the murder investigation team into the death of Miss Marion Ross in 1997. Many fingerprints were found on the crime scene. The Scottish Criminal Record Office (SCRO) in Glasgow examined the fingerprints and attributed one of the latent prints to Mr Asbury and another to Ms McKie. Three fingerprint examiners of the SCRO verified that the one print belonged to Ms McKie.

Mr Asbury was prosecuted and convicted of the murder of Miss Ross. There were no issues at the trial with regards to any of the identifications made by the SCRO. When Ms McKie gave evidence at the trial she was asked about the fingerprint on the doorframe of the bathroom that had been attributed to her. She denied that the fingerprint was hers explaining that she had not been beyond the porch of the house.

Following the trial Ms McKie was prosecuted for perjury. At her trial in 1999 two American fingerprint experts disputed the fact that the print belonged to her. She was unanimously acquitted by the jury.

\footnotetext{
${ }^{131}$ Itiel Dror, David Charlton and Ailsa Péron, (2005) 'Contextual Information Renders Experts Vulnerable to Making Erroneous Identifications' (2006) 156 Forensic Science International 74.

${ }^{132}$ See also Itiel Dror and Simon Cole "The Vision in "Blind" Justice: Expert Perception, Judgement, and Visual Cognition in Forensic Pattern Recognition’ (2010) 17 Psychonomic Bulletin and Review 161.

${ }^{133}$ In HM Advocate v McKie.

${ }^{134}$ See The Fingerprint Inquiry Report (n 115).

${ }^{135} R v$ Smith (n 126).

${ }^{136}$ Then known as Detective Constable Cardwell.
} 
After the acquittal Ms McKie's father raised a number of issues with the Scottish authorities concerning inter alia the expertise and conduct of the fingerprint experts on whose evidence the prosecution relied. He also conducted a campaign through the media, members of Parliament and through others. The case attracted huge media attention. In two television programmes doubt was not only cast on the finding by the SCRO that the one print was made by Ms McKie, but also on the finding of the SCRO that another print was made by Miss Ross.

Due to these events various enquiries were carried out by the police and other public authorities. The findings resulted in doubts being raised about other marks connected with the two cases. When the first of these findings were made public in 2000 the then Minister of Justice, Jim Wallace, informed the Scottish Parliament that Ms McKie's fingerprint had been misidentified and that the bureau was not fully effective and efficient. This led to more investigations and reports by organisations and individuals aligned to the government. Later in 2000 the Court of Criminal Appeal released Mr Asbury from prison pending his appeal against his conviction. The Crown did not oppose his appeal and his conviction was quashed.

Not long after this Ms McKie instituted civil proceedings inter alia against the SCRO and its officers. In 2005 the Scottish Ministers admitted that the SCRO had made a mistake in finding that the print belonged to Ms McKie and indicated that they would settle the case.

In 2006 the First Minister of Scotland told the Scottish Parliament that the misidentification had been an honest mistake. However, it soon became evident that many did not believe this to be the case and the dust was not yet to settle.

In 2008 a Public Judicial Inquiry was set up by the Scottish Ministers to enquire into the steps taken in the identification and verification of the fingerprints associated with the case of HM Advocate v Mckie, the consequences of the steps taken, or not taken, and to recommend measures to ensure that any shortcomings are avoided in future. ${ }^{137}$

The Inquiry published its report in December 2011. The Inquiry found no impropriety on the part of the fingerprint examiners and attributed the misidentifications to human error. The Inquiry found that there were risk factors in the comparison process one of which was the lack of independent verifications. ${ }^{138}$ In its recommendations the Inquiry stressed the need

\footnotetext{
${ }^{137}$ The Fingerprint Inquiry Report (n 115) 'Terms of reference'.

${ }^{138}$ The Fingerprint Enquiry Report ibid ch 28 read with 'Key Findings and Recommendations' ch 42 and 'Recommendations' ch 43.
} 
for independent verification where the reviewer had not had any previous involvement with the fingerprint. ${ }^{139}$

It is reasonable to deduce that the lack of independence played a major role in the failing of the system. It is highly unlikely that four qualified fingerprint examiners working in complete independence would all have misidentified the relevant print as belonging to Ms McKie.

In the second example the English Court of Appeals quashed a homicide conviction. In the case a seventy one year old woman was found dead at her home. The murder accused was her neighbour who was in financial distress and stood to benefit from her will.

Initially the examiner, a police officer with twenty two years' experience concluded that there was insufficient detail for a meaningful comparison. When the examiner heard that the neighbour had been charged, he re-examined the latent print and concluded that he had no doubt that the area of friction ridge detail on the print was made by the neighbour (appellant). Two officers of the same police department verified the identification. At trial all three officers testified to the identification. A defense expert testified that the latent print was useless and that he had never seen a fingerprint officer identify a print of such bad quality.

On appeal the court heard from two retired police print examiners. They suggested that the Crown's examiners had confused furrows with ridges and that they ignored a part of the latent print that excluded the appellant as the source of the bloody print. The Court of Appeals expressed grave dissatisfaction at the police-dominated fingerprint practises in England and Wales, commenting that it was out of step with modern forensic science. The court held that there was a real need for the Association of Chief Police Officers, the Forensic Science Regulator and the recently established Fingerprint Quality Standards Specialist Group to assess the situation and to ensure that there are quality standards enforced through a robust and accountable system.

\section{E Conclusion}

Fingerprint comparison evidence has been associated with a discipline that has been admired and touted as an identification process for many years. However, it appears that the ability of fingerprint examiners to make a conclusive match has been overstated, and the chance of an error concomitantly underplayed. Fingerprint experts disagree markedly as to the quantity of

${ }^{139}$ The Fingerprint Enquiry Report ibid ch 43, Recommendations 29 to 32. 
similarities that are needed for an identification. The methods and approach that are used are also not satisfactory, let alone that what one usually associates with validated science.

I fear that innocent people may be convicted if the status quo is left unchanged. This is especially so in countries like South Africa where the criminal justice system is failing its' citizens every step of the way. ${ }^{140}$ Unfortunately it is fair to say that the South African Police Service is not up to a first world standard and cannot be trusted with the task of performing accurate and unbiased procedures. ${ }^{141}$ It is also not a safe premise to admit the evidence and then to rely on the accused to test the evidence by way of cross examination and contrary evidence. The vast majority of accused in South Africa do not have the means to secure the services of an attorney or an expert fingerprint examiner and the system of state-funded counsel does not adequately protect accused against injustice. In many instances the state appointed attorney only sees the client the first time minutes before the trial starts. ${ }^{142}$

However, this does not mean that fingerprint comparison evidence is 'junk science' and that the evidence should be excluded. ${ }^{143}$ Yet, positive action is necessary. First and foremost I suggest that at least one second independent examiner should review an identification before it is presented as evidence in court. The second examiner must not be from the same agency.

Ideally, it must be a blind procedure where the independent examiner, cognisant of the fact that this will be done, is from time to time also presented with prints that have not been found to be a match. In this way the independent examiner will not know that specific prints have been positively matched.

Fingerprint examiners are furthermore accustomed to regarding their findings as a matter of certainty. Practitioners should be advised of the shortcomings and must be cautioned to give due consideration to the limits of their discipline. This will enable the practitioner to be more objective and to entertain the possibility that the opinion is not correct, before, and when the evidence is presented in court.

\footnotetext{
${ }^{140}$ See for example Emily Pizzale, 'A reflection on South Africa's Criminal Justice System' (2011) at $<$ http://victemempowermentsa.wordpress.com/2011/04/14/14/a-reflection-on-south-africa $\%$ e2\%80\%99scriminal-justice-system/ accessed on 16 June 2012; Legalbrief Today, 'Inept interpreters influencing course of justice-judge' (2012) at <legalbrief.co.za> accessed on 26 June 2012.

${ }^{141}$ There is a considerable lack of necessary skills in the forensic services. See for example Henriëtte Geldenhuys, 'Mystery deaths go unsolved' (2012) at $<$ http://www.iol.co.za/news/crime-courts/mystery-deathsgo-unsolved-1.1326197> accessed on 26 June 2012.

${ }^{142}$ See for example the insert 'Know Your Rights' in the Carte Blanche investigative journalism program on MNet that was broadcast on 10 June 2012. See also carte Blanche, 'Know Your Rights' (2012) at $<\mathrm{http}: / /$ beta.mnet.co.za/carteblanche/> accessed on 16 June 2012.

${ }^{143}$ See Elsayed Mukhtar v Cal State Univ Hayward 299 F 3d 10531063 (9 $9^{\text {th }}$ Cir 2002) (United States Court of Appeal, Ninth Circuit).
} 
Because the process is so subjective, examiners should be required to participate in continuing training with regard to existing procedures and equipment, and new technologies. Where there is an accrediting body it should ensure that examiners have been trained to an acceptable level of competency. ${ }^{144}$

Notes should be made by every examiner at every stage of the process and included in a report to make the interpretive process as transparent as possible. The information should be sufficient to allow another examiner to assess the accuracy and validity of the earlier examiners' assessment and be intelligible to non-experts. ${ }^{145}$

The decision makers and the other actors in the criminal justice process should also be made aware of the limitations of fingerprint comparison evidence. The trial court must not only scrutinise the principles and methods that have been used, but also make sure that those principles and methods have been properly applied on the facts of the case, while paying attention to the burden of evidence.

It is also apparent that further research is required into fingerprint analysis. With regard to the interpretive process, a best practice protocol with regard to sufficiency in the context of an identification should especially be of assistance to some practitioners.

Probabilistic models of various kinds could also be of assistance. At present the weighting of individual features in relation to how frequently it occurs is mainly based on the experience of the specific examiner. Examiners should in weighting the detail at the evaluation stage of the process benefit from data that indicate the frequency of particular features and their configurations. The modelling will also supply objective probabilities that will be valuable for presiding officers and juries to come to conclusions.

\footnotetext{
144 See also The Fingerprint Inquiry Report (n 115) 'Recommendations' ch 43; The Report of the Expert Working Group (n 104) 'Summary of Recommendations' ch 10.

${ }^{145}$ See also The Fingerprint Inquiry Report ibid; The Report of the Expert Working Group ibid.
} 